\title{
Observatório
}

\section{A HISTÓRIA PÚBLICA NO BRASIL ENTRE PRÁTICAS E REFLEXÕES: \\ a oficina historiográfica Interview de Ricardo Santhiago entre a história oral e a história pública \\ Entrevista \\ Entrevista}

\section{Fagno da Silva Soares ${ }^{1,2}$}

"[...] a história pública pode ser entendida em quatro generosas dimensões, passiveis de entrecruzamentos $e$ interpretações: história para o público, história com o público, história feita pelo público e história e público.

Ricardo Santhiago, 2016.

Entrevista realizada durante o $3^{\circ}$ Simpósio Internacional de História Pública: História Pública em Debate no dia 28 de novembro de 2016, na Universidade Regional do Cariri [URCA], com o historiador e

\footnotetext{
${ }^{1}$ Doutor em Geografia Humana pela Universidade de São Paulo (USP), mestre em História do Brasil pela Universidade Federal do Piauí (UFPI), graduado em História pela Universidade do Estado do Maranhão (UEMA). Pesquisador do Núcleo de Estudos de História Oral da Universidade de São Paulo [NEHO/USP] e do Grupo de Pesquisa Trabalho Escravo Contemporâneo da Universidade Federal do Rio de Janeiro [GPTEC/UFRJ]. Líder do CLIO \& MNEMÓSINE Centro de Estudos e Pesquisa em História Oral e Memória [IFMA]. Professor de História do Instituto Federal de Educação, Ciência e Tecnologia do Maranhão [IFMA/Campus Açailândia]. E-mail: fagno@ifma.edu.br. Endereço postal: Rua Projetada, s/n, Progresso, 65930000, Açailândia, MA, Brasil.

${ }^{2}$ Endereço de contato do autor (por correio): Rua Projetada, s/n, Progresso, CEP: 65930-000, Açailândia, MA, Brasil.
} 


\section{Crevisto}

ISSN n² 2447-4266

Vol. 3, n. 2, Abril-Junho. 2017

DOI: http://dx.doi.org/10.20873/uft.2447-4266.2017v3n2p569

comunicólogo Ricardo Santhiago, é professor da Universidade Estadual de Campinas [UNICAMP]. É pesquisador do Laboratório de História Oral e Imagem [LABHOI-UFF], do GEPHOM - Grupo de Estudo e Pesquisa em História Oral e Memória [EACH-USP]. Fundador e membro da coordenação da Rede Brasileira de História Pública [RBHP] no Brasil.

Ricardo Santhiago, pesquisador com pujante produção historiográfica acerca dos aspectos teórico-metodológicos da história oral e da história pública no Brasil. É pós-doutor em História pela Universidade Federal Fluminense [UFF, 2015], doutor e mestre em História Social [USP, 2013/2009], especialista em Jornalismo Científico [Unicamp, 2006] e graduado em Jornalismo [PUC-SP, 2004]. Atualmente é professor da Faculdade de Ciências Médicas da Universidade Estadual de Campinas, pesquisador do Laboratório de História Oral e Imagem [LABHOI-UFF], do GEPHOM - Grupo de Estudo e Pesquisa em História Oral e Memória [EACH-USP] e do MusiMid - Centro de Estudos em Música e Mídia [ECA-USP]. É fundador da Rede Brasileira de História Pública [RBHP], associado à Oral History Association [OHA, USA]; a Associação Brasileira de História Oral [ABHO] e da National Council on Public History [NCPH, USA]. Em sua profícua produção intelectual, destacamos dentre outras obras das quais é autor e/ou [co]organizador: Solistas dissonantes: História [oral] de cantoras negras [2009], Narrativas e Experiências: Histórias orais de mulheres brasileiras [2009], Memória e diálogo: Escutas da Zona Leste, visões sobre a história oral [2011], Depois da utopia: A história oral em seu tempo [2013], História oral na sala de aula [2015] e História pública no Brasil: Sentidos e itinerários [2016], História oral e arte: Narração e criatividade [2016]. Seu artigo The Dissonant Lives of Brazilian Black Women Singers, publicado em 2012 pela revista Oral History Journal, rendeu-lhe o prêmio "Article Award da Oral History Association" de melhor artigo de história oral. Em 2104 foi laureado com o prêmio "New Professional Award do National Council on Public History".

Recebido em: 19.03.2017. Aceito em: 26.03.2017. Publicado em: 01.04.2017. 


\section{Orevisto}

ISSN n² 2447-4266

Vol. 3, n. 2, Abril-Junho. 2017

DOI: http://dx.doi.org/10.20873/uft.2447-4266.2017v3n2p569

Durante a entrevista, Ricardo Santhiago tratou de sua trajetória profissional, e fez inúmeras reflexões acerca da conceituação, trajetória e experiências da história pública no Brasil. Falou de seus projetos em andamento e de seu contributo na ampliação das reflexões teórico-metodológicas à história pública brasileira.

Fagno da Silva Soares [FSS]: Boa tarde, caro professor Ricardo. Agradecemos a disponibilidade em conceder-nos esta entrevista, e, por conseguinte, registramos nossa satisfação. Destarte, tomemos como mote inicial desta entrevista, a sua trajetória profissional, bem como, as motivações que o levaram à escolha da carreira de jornalista, e posteriormente, a de historiador. Neste sentido, recordamo-nos de seu artigo publicado na $\mathrm{PJ}: \mathrm{Br}$ - Jornalismo Brasileiro em 2007, cujo título "Esboço para um diálogo: História oral e jornalismo de grande extensão" traduz bem seu intento, ao tratar dos ditos, interditos e possibilidades no diálogo entre história oral e jornalismo. Dito isto, perguntamos-lhe, você se considera um jornalista-historiador ou um historiador e jornalista? Quais as implicações e desdobramentos resultantes da interface e/ou fronteira entre história e jornalismo?

Ricardo Santhiago [RS]: Fagno, primeiramente agradeço seu convite tão gentil. Não sei se minha resposta a essa pergunta vai ser satisfatória. A verdade é que eu não sinto nenhuma ruptura na minha trajetória; pelo contrário, as coisas que fiz e que explorei, dentro e fora da universidade, sempre vieram como resultado de indagações surgidas do próprio trabalho - um trabalho 


\section{Orevisto}

ISSN n² 2447-4266

Vol. 3, n. 2, Abril-Junho. 2017

DOI: http://dx.doi.org/10.20873/uft.2447-4266.2017v3n2p569

poucas vezes de jornalista, algumas vezes de produtor cultural, várias vezes de historiador, mas sempre de pesquisador. Há várias afinidades entre essas duas profissões que você traz, mas há jornalismos e jornalismos, histórias e histórias, e a história oral é só um ponto de encontro entre vários possíveis. Hoje já há dezenas, se não centenas, de artigos e teses sobre isso, especialmente à luz da história do tempo presente, que respondem à segunda parte da sua pergunta com a profundidade necessária. Quanto à primeira, também é difícil, mas vamos lá. Há alguns anos fui pela primeira vez a uma livraria quando estava viajando e comprei três livros. O homem que me atendeu, que era provavelmente o dono da livraria e devia estar ali há décadas - algo cada dia mais raro, infelizmente olhou para mim e disse: "Ah, muito bem: você é um historiador cultural!". Foi um ótimo palpite, e uma experiência quase incômoda, essa de ser tão facilmente decifrável. Mas acho que eu acrescentaria algumas coisas naquela definição e diria que eu sou alguém que faz pesquisa histórico-sociológica, muito interdisciplinar, sobre a vida cultural e intelectual brasileira no presente, e tendo a memória e a comunicação (pessoal e/ou midiática, ou social, como preferir) como eixos sempre presentes. Embora as pesquisas que eu venho desenvolvendo pareçam bastante diferentes umas das outras, tanto em termos temáticos quanto de procedimento, todas remetem, em maior ou menor medida, a esse lugar - um lugar, repito, muito interdisciplinar, e essa é uma característica que eu acredito ser bem evidente no meu trabalho.

FSS: Agora, fale-nos um pouco das influências historiográficas que teve durante seu mestrado e doutorado em História Social na Universidade de São Paulo [USP] e em seu estágio pós-doutoral no Laboratório de História Oral e Imagem 


\section{Gevisto
Observatório}

ISSN n² 2447-4266

Vol. 3, n. 2, Abril-Junho. 2017

DOI: http://dx.doi.org/10.20873/uft.2447-4266.2017v3n2p569

[LABHOI/UFF]. Quais historiadores exerce[ra]m papel importante na sua formação inicial de jornalista e continuada de historiador? Parafraseando Marc Bloch, para que serve a história pública?

Ricardo Santhiago: O que costura esses três momentos é, com certeza, a história oral. E talvez o que tenha sido a semente para o meu interesse em história pública tenha vindo antes disso - fiz um curso de especialização na Unicamp, ministrado pelo Laboratório de Estudos Avançados em Jornalismo, voltado à divulgação científica. Ali tive contato com discussões fascinantes sobre ciência, tecnologia e sociedade, mas o que me chamou muita atenção foi que havia uma ênfase tão grande na divulgação de pesquisa em ciências biológicas e da saúde que acabava deixando quase nenhum espaço para problematizar isso no âmbito das ciências humanas e sociais. Essa preocupação com a comunicação, com a socialização da pesquisa histórica, vem um pouco daí. E vem também de um certo desajuste pessoal, porque quando eu entrei no território do historiador eu simplesmente dava por certo esse impulso de comunicar o resultado da pesquisa acadêmica para o público mais amplo e mais variado possível. Bem, depois eu vi que não era bem assim. E ainda mais tarde vi também que a história pública não pode ser resumida a essa função divulgadora - e acho muito importante frisar isso, já que não vejo história pública e divulgação científica da história como sinônimos.

Mas, voltando à sua pergunta, eu acredito que tenham sido três momentos muito saudáveis e de muita ativação intelectual. No mestrado, como você sabe, tive como orientador o professor José Carlos Sebe Bom Meihy, praticante e teórico da história oral, que me deu um estímulo muito forte e que de certa forma viabilizou meus primeiros gestos de envolvimento com esse tema e com 


\section{Orevisto}

ISSN n² 2447-4266

Vol. 3, n. 2, Abril-Junho. 2017

DOI: http://dx.doi.org/10.20873/uft.2447-4266.2017v3n2p569

essa área, para além da aplicação mais imediata, digamos assim, da história oral como um método que estava solucionando um problema de pesquisa. Passei três anos no Núcleo de Estudos em História Oral da USP, com um envolvimento muito intenso, que transparece nos meus primeiros escritos e com certeza no livro Solistas dissonantes, embora ele seja, já, um tanto quanto diferente da dissertação que lhe deu origem, até pela preocupação mais evidente com a história pública. Na verdade, ao longo daquele período de estudo e de formação, eu descobri que eu tinha mais afinidades com os trabalhos temáticos do núcleo (e eu diria até que bastante afinidade) do que com a visão, tanto metodológica quanto política, de história oral que predominava no grupo. Do meu ponto de vista, isso foi extremamente positivo, tendo vários desdobramentos - começando pela minha tese de doutorado.

Meu contato próximo com a história oral também ativou muito o interesse na história pública - já que, como você sabe, elas têm uma relação muito íntima. Primeiro, porque o público é uma condição para que a história oral se realize. Segundo, porque boa parte das pesquisas no campo da história oral são caracterizadas por aquele impulso de oferecer visibilidade às histórias de indivíduos e de grupos que não fazem parte do registro histórico - o que eu acho válido e importante, embora ache também que a pesquisa acadêmica não pode se resumir a isso. Eu não canso de dizer que uma das coisas mais perspicazes que já li sobre o sentido da história oral é aquilo que a Marieta de Moraes Ferreira desenvolve: a história oral como uma espécie de bússola para os desafios da história, como uma prática que faz as vezes de um "laboratório epistemológico" valiosíssimo porque radicaliza aspectos que dizem respeito à prática historiadora como um todo mas que ficam mais visíveis, mais aguçados, 


\section{Orevisto}

ISSN n² 2447-4266

Vol. 3, n. 2, Abril-Junho. 2017

DOI: http://dx.doi.org/10.20873/uft.2447-4266.2017v3n2p569

no trabalho com a história oral (e com a memória, com o tempo presente, com a subjetividade, com a intersubjetividade, com a demanda social, e assim por diante).

Fagno Soares: Compreendemos, pois o campo da história pública com um espaço de natureza interdisciplinar que intersecciona, a história para o público com a história e o público, potencializadas por diferentes linguagens como a cinematográfica, iconográfica, literária, museológica e/ou midiática. Neste sentido, qual o desafio dos profissionais que atuam neste campo? Em que medida o fato de ser jornalista e historiador tem contribuído em suas práticas e reflexões com a história pública?

Ricardo Santhiago: Essa é uma boa pergunta, porque abre caminho para pensar a história pública não só como um espaço interdisciplinar, mas como uma prática multidisciplinar. $\mathrm{O}$ historiador precisa conhecer as diferentes linguagens e os vários suportes à disposição para comunicar sua pesquisa, mas não pode, e talvez nem deva, dominar todos eles. É mais importante compreender a linguagem cinematográfica do que saber usar o software de edição de vídeo do momento, embora também seja interessante e muitas vezes útil ter competência para atuar nas diferentes etapas de elaboração de um trabalho. Penso nessa colaboração multiprofissional inclusive como solução para o dilema da formação para a história pública - mais uma vez, me pergunto se é realmente necessário ter um curso de perfil essencialmente técnico, como são vários cursos estrangeiros na área, ensinando coisas que rapidamente vão se tornar obsoletas, e num nível muito superficial. Não dá para se tornar 


\section{Qrevisto}

ISSN n² 2447-4266

Vol. 3, n. 2, Abril-Junho. 2017

DOI: http://dx.doi.org/10.20873/uft.2447-4266.2017v3n2p569

especialista em vídeo e em internet e em história oral e em rádio e em escrita criativa e em curadoria e em administração de arquivos, muito menos no curso de, digamos, dois anos - tempo que poderia ser melhor investido. Nesse sentido, a parceria com escolas e cursos de comunicação é, além de completamente viável, muito enriquecedora para todos os lados, quando se trata da história pública praticada dentro da universidade.

Fagno Soares: Sabemos da importante contribuição e lastro da historiografia norte-americana à história pública. Apresente-nos alguns autores/obras que você considera que sejam seminais a história pública no mundo. Existem iniciativas de tradução destas obras estadunidenses para o português?

Ricardo Santhiago: Pessoalmente, aprendi e aprendo muito lendo os autores estrangeiros: os estadunidenses como também, no caso da história pública, os canadenses, os australianos e talvez principalmente os britânicos (para ficar apenas na língua inglesa, onde a discussão está consolidada sob esse rótulo). Foi nos Estados Unidos que "descobri", como várias outras pessoas, que aquele conjunto de coisas em que eu vinha pensando tinha um nome. Agora, não vejo que nenhum desses trabalhos tenha sido "seminal" para a prática da história pública em si. Pelo contrário: o que vejo, no movimento internacional recente, é uma inclinação perigosa de indivíduos e instituições que renegam as experiências de outros países porque são diferentes das que professam. Mas isso está longe de ser uma especificidade dessa área. No simpósio de história pública realizado na UFF, em 2014, falei justamente sobre a importância de reconhecimento das diferentes experiências nacionais e regionais. $E$, mesmo 


\section{Oeveristo}

ISSN n² 2447-4266

Vol. 3, n. 2, Abril-Junho. 2017

DOI: http://dx.doi.org/10.20873/uft.2447-4266.2017v3n2p569

que os autores de textbooks não ouçam, já somos bem capazes de discernir colonialismo cultural de diálogo e intercâmbio verdadeiros.

Fagno Soares: Em 2011 fomos agraciados pela Editora Letra e Voz com a publicação da obra seminal, "Introdução à História Pública" organizada pelas professoras Juniele Rabêlo e Marta Gouveia Rovai. Mais recentemente, com a publicação da obra coletiva "História pública no Brasil: Sentidos e itinerários" sob a sua organização e das Professoras Ana Mauad e Juniele Rabêlo trazendo um conjunto de reflexões teóricas, metodológicas e práticas sobre história pública. Certamente estas obras já nasceram clássicas, senão tornarão-se em breve, a exemplo da coletânea lançada nos fins dos anos 90, "Usos de Abusos da história oral" organizada pelas professoras Marieta de Moraes Ferreira e Janaína Amado e lançada pela Editora da Fundação Getúlio Vargas. Num breve retrospecto da chegada, disputas conceituais e desenvolvimento da história pública no Brasil, como você analisa o avanço deste campo dentro e foras das universidades brasileiras?

Ricardo Santhiago: A história pública no Brasil segue uma trajetória própria, bem diferente, por exemplo, daquela que trilhou nos Estados Unidos, onde ela aparece nos anos 1970 como uma tentativa esclarecida da comunidade de historiadores em abrir novos campos de trabalho, sobretudo com a diminuição dos postos nas universidades e, ao mesmo tempo, com a proliferação de novos doutores. Costumo dizer que o maior êxito do movimento de história pública americano não tenha sido propriamente esse, de abrir novos campos de trabalho (embora certamente tenha ajudado nisso), mas o de fundar toda uma 


\section{Orevisto}

ISSN n² 2447-4266

Vol. 3, n. 2, Abril-Junho. 2017

DOI: http://dx.doi.org/10.20873/uft.2447-4266.2017v3n2p569

nova área, o que implica novos postos de trabalho, novos espaços de reconhecimento, novas instâncias de poder. A história pública americana hoje se apresenta como uma disciplina um tanto quanto apartada da disciplina histórica, sobretudo em função da necessidade de preservação desse espaço institucional. Certos professores afirmam abertamente que só pode fazer história pública quem fez um curso de história pública; se não, você está fora do clube. Acho que esse é um caminho problemático, até porque "historiador público" não é uma profissão. A Ana Maria Mauad sugere que talvez deveríamos entender a história pública como uma "atitude" e eu gosto dessa ideia. Mas no ambiente americano há várias exceções e é com elas que eu prefiro dialogar: com o Michael Frisch, com a Linda Shopes, com a Denise Meringolo. No Brasil, houve um breve momento de reticência em relação à história pública (talvez até por esse histórico estrangeiro um tanto quanto separatista), sucedido por um interesse genuíno de compreensão - e acho que isso resulta principalmente desse esforço coletivo que está consubstanciado nessas duas coletâneas e na própria constituição da Rede Brasileira de História Pública. Hoje, vejo cada vez mais disciplinas sobre história pública em cursos de graduação e pósgraduação, em bibliografias para seleções de mestrado e doutorado e até de concursos públicos. E isso quase sempre nessa perspectiva, que eu considero mais promissora, de integração - embora seja interdisciplinar e multiprofissional, o lugar da história pública é fundamentalmente o da História, com quem compartilha seus objetos e métodos.

Fagno Soares: Neste contexto, a Rede Brasileira de História Pública [RBHP] tem contribuido para a ampliação e consolidação das reflexões teórico-práticas 


\section{Qrevisto}

ISSN n² 2447-4266

Vol. 3, n. 2, Abril-Junho. 2017

DOI: http://dx.doi.org/10.20873/uft.2447-4266.2017v3n2p569

acerca da história pública no Brasil. Em geral, a história pública rompe a barreira da academia, atingido outros espaços de produção e circulação do saber histórico atingindo outras audiencias. Destarte, fale-nos sobre as perspectivas e de algumas experiências, bem como, das tendências este campo no Brasil.

Ricardo Santhiago: Fico feliz em saber que esse novo panorama resulta, pelo menos em parte, desses esforços da Rede. Desde o primeiro curso de história pública, em 2011, muitas pessoas se integraram ao movimento. Num primeiro momento, um grupo mais ligado à história oral, mas hoje isso está bastante espraiado. A história pública foi se complexificando à medida que foi sendo integrada a debates em torno do patrimônio, da educação e do ensino de História, da história digital, da história do tempo presente. Acho que a tendência é que isso se intensifique, em última instância tornando até irrelevante o próprio movimento de história pública - eu sempre brinco dizendo que essa é a meta final.

Fagno Soares: Em sua tese, desenvolvida no Programa de Pós-Graduação em História Social da Universidade de São Paulo [PPGHS/USP], Método, metodologia, campo: A trajetória intelectual e institucional da história oral no Brasil, sob a orientação da professora Sara Albieri, você realizou um estudo um denso estudo acerca da trajetória da história oral em terras brasileiras, entrevistando grandes pesquisadores responsáveis pelo processo de consolidação da história oral no Brasil. Trata-se de um estudo inaugural no Brasil que fez frente ao início da constituição narrativa da história oral no Brasil. Neste sentido, compartilhe conosco qual o contributo deste estudo para a história da história oral. E como você situa sua tese de doutoramento neste contexto? 


\section{Orevisto}

ISSN n² 2447-4266

Vol. 3, n. 2, Abril-Junho. 2017

DOI: http://dx.doi.org/10.20873/uft.2447-4266.2017v3n2p569

Ricardo Santhiago: Por várias razões, o processo de pesquisa e de escrita dessa tese, que não foi publicada, foi desafiador. O problema do pesquisador insider era central - e, pensando retrospectivamente, foi por isso mesmo que eu busquei me afastar tanto quanto pude das "fontes orais", ou melhor, dos personagens cujo trabalho analisei. As entrevistas que você menciona só apareceram bem mais tarde no processo de pesquisa - depois de eu ter lido praticamente tudo o que se publicou sobre história oral entre os anos 1950 e os anos 2000 e depois de eu ter feito uma boa pesquisa em arquivos, tanto institucionais quanto pessoais. Eu até ousaria dizer que a função principal das entrevistas na tese tenha sido a de "preencher lacunas". Depois, outras possibilidades de aproveitamento apareceram, mas ainda assim ela não é um trabalho de história oral, e sim uma história intelectual cujas principais fontes são as produções bibliográficas dessa área. $\mathrm{O}$ trabalho ficou extenso demais e por várias razões ainda não cheguei a um formato que eu consideraria aceitável para publicar, mas consigo reconhecer que ele tem algumas contribuições. Primeiro, o de questionar, ampliando, as "narrativas de fundação" da história oral no Brasil, que privilegiam um modelo institucional (a história oral arquivística) em detrimento de outros que o precedem, que coexistem e que até hoje têm um papel importante na formação de novos pesquisadores e de grupos de pesquisa. Então, minha interpretação é um convite para entendermos a história oral feita no Brasil como um conjunto de misturas feito a partir de quatro matrizes, que ao longo do tempo vão se combinando, em proporções variadas: a história oral de matriz sociológica, que enfatiza o debate metodológico, procedimental; a história oral mais ligada à Psicologia Social, muito encarnada na figura da Ecléa Bosi, que traz para o centro da mesa a importância da memória, da linguagem, da atenção; a história oral "de 


\section{Orevisto}

ISSN n² 2447-4266

Vol. 3, n. 2, Abril-Junho. 2017

DOI: http://dx.doi.org/10.20873/uft.2447-4266.2017v3n2p569

inspiração pública", com toda a experiência das várias unidades do Museu da Imagem e do Som e de obras publicadas com a intenção de intervir na vida pública; e a história oral arquivística, conectada ao modelo americano da Universidade de Columbia e que, até pela força institucional do Centro de Pesquisa e Documentação de História Contemporânea do Brasil [CPDOC/FGV], acabou vingando na literatura sobre nossa área como o modelo fundador. Isso tudo se apoia em alguns conceitos operacionais, principalmente na identificação de três gerações que cumprem funções diferentes no desenvolvimento do campo, e na distinção entre método, metodologia e campo, que dá título ao trabalho. O segundo ponto importante do trabalho, a meu ver, consistiu em ressaltar a complementaridade e a influência mútua entre o trabalho intelectual e a política institucional nos esforços para a consolidação e a manutenção do campo da história oral no Brasil, bem como para sua internacionalização - algo um pouco mais controverso, mas que eu analiso a partir da noção de um "projeto" de organização e disciplinação de um campo, corporificada no "imperativo do projeto de pesquisa". Infelizmente não tenho espaço para detalhar isso aqui, mas espero conseguir reformular o trabalho, começando por torná-lo mais enxuto do que as indigestas quase 600 páginas que ele tem. Acredito que ele pode contribuir para elucidar aspectos pouco conhecidos ou problematizados dessa "trajetória intelectual e institucional" da história oral no Brasil, especialmente quando somado a outras interpretações já publicadas - essas sim inauguradoras -, sobretudo as da Marieta de Moraes Ferreira, que foi quem mais se dedicou ao assunto. 


\section{Orevisto}

ISSN n² 2447-4266

Vol. 3, n. 2, Abril-Junho. 2017

DOI: http://dx.doi.org/10.20873/uft.2447-4266.2017v3n2p569

Fagno Soares: Fale-nos um pouco de sua pesquisa de pós-doutoramento, desenvolvida junto ao Laboratório de História Oral e Imagem da Universidade Federal Fluminense [LABHOI/UFF], sob a supervisão da Profa. Ana Maria Mauad, que resultou no belíssimo artigo que tivemos a oportunidade de ler, durante um curso ministrado pela Profa Ana Maria Mauad, "História Pública como prática e campo de reflexões: debates, trajetórias e experiências no Brasil," no qual você trata de quatro modalidades das quais chama de elementares à história pública.

Ricardo Santhiago: O LABHOI é um dos pontos de referência da história pública no Brasil, seja no que diz respeito ao papel público do historiador, ao papel da história como propulsora de políticas públicas, à escrita videográfica da história. Tive o prazer e o privilégio de fazer esse estágio pós-doutoral lá, trabalhando com a supervisão da professora Ana Maria Mauad, e de poder trabalhar um pouco na sistematização das práticas de história pública. $\mathrm{Na}$ realidade, o que propus no estudo foi que desenvolvêssemos uma visão mais generosa e abrangente da história pública, escapando a modelos prescritivos, geralmente importados, e isso passa por um trabalho de mapeamento das diferentes atividades que manejam, de forma mais ou menos explícita, os princípios da história pública. Esse é um trabalho que está por ser feito, e que só pode ser feito coletivamente. De qualquer forma, de maneira um pouco impressionista, tentei reduzir toda essa variedade de práticas a esses quatro engajamentos principais da história pública: a história feita para o público (baseada na ideia de ampliação de audiências e de ocupação de novos postos de trabalho), a história feita pelo público (baseado no reconhecimento de variações não acadêmicas, e em geral não profissionais, da escrita da história), a 


\section{Orevisto}

ISSN n² 2447-4266

Vol. 3, n. 2, Abril-Junho. 2017

DOI: http://dx.doi.org/10.20873/uft.2447-4266.2017v3n2p569

história feita com o público (próxima de uma história colaborativa, muito avizinhada à história oral e, mais recentemente, à cultura digital) e história $e$ público (como uma rubrica comum a uma série de reflexões que já têm sido feitas sob chaves como usos do passado, usos da memória, etc.). Algumas pessoas já propuseram outras tipologias, de modo que esse é um exercício carente de ineditismo - mas o que eu tentei fazer foi ampliar esse quadro de modo que ele não se reduzisse à defesa de uma ou de outra perspectiva, algo bastante comum na literatura estrangeira, e ao mesmo tempo reduzi-lo tentando identificar com clareza as problemáticas transversais de cada modalidade. Além do mais, essa é uma divisão meramente didática, já que as práticas se entrecruzam.

Fagno Soares: Chegou até nós, a informação que tem desenvolvido um livro em parceira com a professora Daphne Patai. O que o público pode aguardar desta obra?

Ricardo Santhiago: Você tinha me perguntado, antes, quais historiadores tiveram um papel importante na minha formação. A Daphne Patai não é historiadora, mas o trabalho dela moldou muito aquilo que penso sobre história oral - tanto quando faço história oral quanto quando penso sobre o desenvolvimento desse método e desse campo. Foi o trabalho dela que me mostrou que a história oral poderia ser um caminho, antes mesmo de eu iniciar minha pesquisa de mestrado Acontece que, de leitor entusiasmado, me tornei um interlocutor frequente, e a certa altura sugeri a Daphne que revisitássemos o trabalho que ela fez nos anos 1980 e que resultou no livro Brazilian Women 


\section{Crevisto}

ISSN n² 2447-4266

Vol. 3, n. 2, Abril-Junho. 2017

DOI: http://dx.doi.org/10.20873/uft.2447-4266.2017v3n2p569

Speak, de 1988, que foi uma coletânea de histórias de vida de mulheres brasileiras, precedidas por aquela introdução fantástica que acabei traduzindo depois e que eu vejo circular muito, felizmente. Então, o que fiz foi reentrevistar as mesmas mulheres que Daphne havia entrevistado entre 1981 e 1983 - pelo menos as que encontrei e que aceitaram falar. Gravei cerca de quinze longas entrevistas que são a base para esse livro que estamos escrevendo. É difícil visualizar o resultado durante o processo, porque há muitas chaves de reflexão que vamos descobrindo: a história dos dois processos de investigação é, em si, completamente distinta, em função dos climas culturais e políticas, das circunstâncias institucionais de realização... E tudo assim, assim como as próprias histórias, abre caminho para pensar as rupturas e as continuidades entre os anos 1980 e os anos 2010. As histórias que gravei são todas fascinantes, cada uma a seu modo. Agora, estamos percorrendo o difícil caminho analítico, interpretativo: de entender de que forma as histórias pessoais, em seus dois tempos, remetem a mudanças culturais mais amplas; de investigar como e por quê as pessoas se narram de um modo ou de outro, num momento ou em outro... Enfim, é um trabalho em processo, e as dificuldades começam justamente pela ausência de modelos. Até agora, as experiências de trabalho com conjuntos de entrevistas separados por um intervalo tão grande foram reduzidas - pelo menos no campo da história oral, já que outras áreas, como a própria Psicologia, trabalham há tempos com estudos longitudinais, sem falar no cinema, nas artes... Mas a questão é: como mobilizar o instrumental do nosso campo para pensar esses diferentes tempos da memória narrada. 


\section{Gevisto}

ISSN n² 2447-4266

Vol. 3, n. 2, Abril-Junho. 2017

DOI: http://dx.doi.org/10.20873/uft.2447-4266.2017v3n2p569

Fagno Soares: Por fim, agradecemos sua entrevista e fazermos a última pergunta. Que conselhos traz aos jovens historiadores que desejam trilhar pelos caminhos da história pública?

Ricardo Santhiago: Fagno, agradeço a entrevista e parabenizo pelo empenho e pelo dossiê que vocês da Revista Observatório [UFT/UNESP] estão preparando. Não me arrisco a oferecer conselhos, mas eu posso concluir reafirmando que vejo a história pública como uma prática fascinante e como um assunto promissor, e que até por isso exige alguma cautela. Finalizo convidando os leitores para se aproximarem da Rede Brasileira de História Pública e participarem do próximo encontro, em 2018.

\section{REFERÊNCIAS}

ALMEIDA, Juniele Rabelo de \& ROVAI, Marta Gouveia de Oliveira. Introdução à história pública. São Paulo: Letra e Voz, 2011. 251p.

- MAUAD, A. M. [Org.]; SANTHIAGO, Ricardo [Org.]. História pública no Brasil: Sentidos e itinerários. 1. ed. São Paulo: Letra e Voz, 2016. v. 1. 352p. 